\title{
Comprehensive study of Malus genus resources for the creation of adaptive grades
}

\author{
Elena Ulyanovskaya*, and Evgenia Belenko
}

Federal State Budget Scientific Institution «North Caucasian Federal Scientific Center of Horticulture, Viticulture, Wine-making», 350901, 39, str. 40 Let Pobedy, Krasnodar, Russian Federation

\begin{abstract}
The breeding renewal of the apple assortment in the conditions of southern fruit growing in Russia on the basis of domestic achievements is due to the acceleration of the breeding process associated with an indepth study of the existing gene pool of culture, the widespread use of the samples most valuable in terms of the quality of the products obtained to create commercially demanded grades of regional breeding. The aim of the study is to isolate, on the basis of a long-term comprehensive study in the conditions of the Western Ciscaucasia, valuable specimens of the genus Malus to enhance the efficiency and accelerate the process of creating adaptive and high-quality grades of regional breeding. The work was carried out using generally accepted and modern programs and methods of variety study and selection of perennial fruit crops (apple trees). The longterm results of the study for 2010-2020 are summarized. in the conditions of the Kuban zone of the North Caucasian region of gardening of collection specimens of apple trees. Established that the increase in hightemperature stressors, the deficit in August of precipitation $(28.2 \mathrm{~mm})$ in recent years (2010-2020) has a negative impact on the growth, development and ripening of fruits, the laying of generative buds of the next year's harvest. The weather conditions that have developed in the region, which are not sufficiently favorable for apple plants, make it possible to select drought-resistant, high-yielding, stably fruiting grades with commercially valuable fruits. Highlighted with high productivity potential diploids: $12 / 1-21-60,12 / 2-20-22,12 / 2-20-75$ and triploids: $12 / 2-$ $21-35,12 / 2-20-56$ (average yield 28.06-34.08 t/ha; total - up to 374.88 $\mathrm{t} / \mathrm{ha}$ ). Diploids were distinguished by large-fruited: Orpheus and 12/1-2160 (average fruit weight 202.3-204.5 g, maximum - 224.8-278.8 g) and triploid varieties and elite forms (from the family of Idared $\times$ Balcgard 0247E): 12/2-21-35, 12/2-20-56, 12/1-21-27 (average fruit weight 201.4$317.9 \mathrm{~g}$, maximum $-286.5-387.2 \mathrm{~g}$ ).
\end{abstract}

\section{Introduction}

Classical breeding of perennial most important agricultural plants, including the main fruit crop - apple (Malus $\times$ domestica Borkh.), Is a rather laborious, energy-consuming and

\footnotetext{
*Corresponding author: ulyanovskaya_e@mail.ru
} 
time-consuming process. Despite the fact that in recent years there has been a tendency for its reduction $[1,2]$, various methods and ways of improving its efficiency and significant acceleration are still relevant [2-5]. One of the ways to achieve high breeding results in the world in the shortest possible time for the most valuable fruit plants, including the apple tree, is an in-depth study of the entire genetic potential of biological resources of crops, especially with the use of modern methods of molecular genetics, cytology, biochemistry, information technology, etc., for active targeted use in the breeding process [3, 7-10].

Often, the increased use in modern breeding technologies and programs of only a limited number of original forms, even very high quality ones, can cause a significant reduction in the biodiversity of hybrid offspring, which reduces the likelihood of a quick and accurate solution of the set breeding problems [7]. Biodiversity is also of great importance for promising, preventive, as well as the so-called "breakthrough" breeding areas, for example, the creation of grades and hybrids with a complex high resistance to abio- and biostressors of the cultivation region, as well as with an improved taste, aroma, color, shape, size, biochemical composition, ripening period and shelf life of fruits.

To successfully solve these important problems for fruit crops in the modern world, it is still important to use classical methods: distant hybridization, including interspecies, rehybridization, polyploidy, spontaneous and induced mutagenesis, etc. The use of interspecific hybridization is aimed at improving the commercial attractiveness of the material being created and the biochemical composition of the fruits, enhancing the signs of resistance to bio- and abiotic stress factors, which is associated with high productivity and stable fruiting of the obtained sample under the influence of stressors [3, 10, 11]. Classical breeding methods of induced polyploidy, clone breeding, induced mutagenesis and distant hybridization can enhance the biodiversity of the resulting hybrid material, increase the number of different variations in the combination of leading agrobiological traits in hybrid offspring, accelerate and increase the likelihood of obtaining valuable samples $[5,6,12]$. Often, according to the most valuable breeding characteristics for a culture, species and semi-cultural forms, interspecific hybrids, polyploids, local grades, as well as varieties and forms obtained on their basis are more capable of exhibiting inherited variability [13-15]. In order to intensify the process of creating domestic grades with the maximum complex of the most valuable qualities in the context of the increased impact of environmental stressors on a perennial plant, it is necessary to develop an information infrastructure, mobilize, preserve and study bioresource collections, including the inclusion in the breeding of a new source material with target traits based on the results of many years of research [10, 16-19]. The aim of the study is to isolate, on the basis of a long-term comprehensive study in the conditions of the Western Ciscaucasia, valuable specimens of the genus Malus to enhance the efficiency and accelerate the process of creating adaptive and high-quality grades of regional breeding.

\section{Methods}

The objects of research are varieties of the genetic collection of the apple tree (Malus $x$ domestica Borkh.) of various ploidy and origin. Experimental plantations of apple trees (planting in 2000-2004, according to schemes of $5 \times 1.5 \mathrm{~m}$ and $5 \times 2 \mathrm{~m}$; on the M9 rootstock) are located in the Kuban zone, the central subzone of horticulture of the North Caucasian region of the Russian Federation. The location of the collection of the general resources of the apple tree NCFSCHVW is the experimental production farm "Centralnoye" (city of Krasnodar). The study was carried out with the financial support of the Kuban Science Foundation in the framework of the scientific project No. IFR - 20.1/92. Research work was carried out according to breeding programs and methods: "Program of the North Caucasus Center for the selection of fruit, berry, flower and ornamental crops and grapes 
for the period up to 2030"; "Modern methodological aspects of the breeding process organization in horticulture and viticulture"; "Program and methodology of variety studies of fruit, berry and nut crops" [20-22].

\section{Results}

In order to maximize the high productivity of perennial apple trees, the leading fruit crop, in the conditions of southern horticulture, as well as the good quality of the fruit products obtained, it is necessary to know the basic limits of the reaction of cultivated varieties to uncontrolled stressors of the region.

In the conditions of the south of Russia, the main stressors of the summer period are drought, prolonged, prolonged high-temperature stressors, a prolonged shortage of precipitation during the growing season, as well as uneven distribution of precipitation and unstable moisture regime of the plant during the setting, formation, growth, development of fruits, laying of fruit buds of the future harvest $[4,5,14,19]$.

In the conditions of southern horticulture, complex resistance to the effects of stressors during the growing season is important for the successful realization of the biopotential of productivity of the varietal composition of apple trees. In the last decade (2010-2020), there has been a significant increase in the average and maximum air temperature in comparison with long-term values, especially in August - the most important period of fruit growth and ripening (Figure 1).

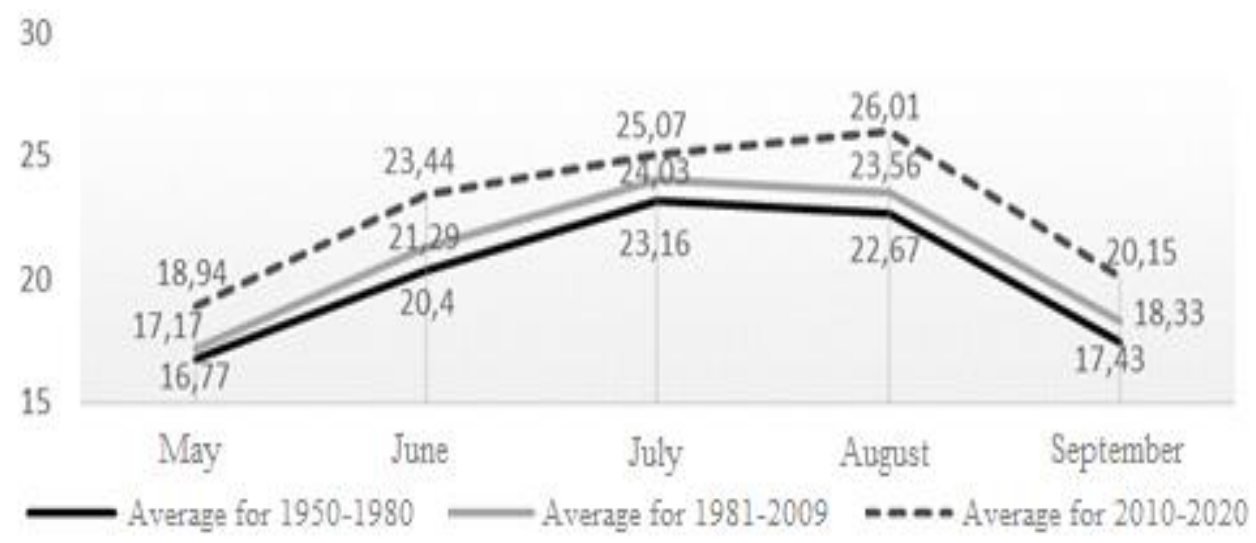

Fig. 1. Average monthly air temperature $\left({ }^{\circ} \mathrm{C}\right)$ from May to September (Krasnodar, central subzone of the Prikuban zone of the North Caucasus horticulture region, 1950-2020).

In addition, in recent years (2010-2020), there has been an increase in the amount of precipitation during the growing season of the apple tree (Figure 2), which, in combination with an increase in the average air temperature, provokes an earlier and stronger development of fungal diseases. Intensification of high-temperature stressors, a significant decrease and a serious deficit in August in the amount of precipitation in the period 2010$2020(28.2 \mathrm{~mm})$ in comparison with the period 1950-1980 (48.0 $\mathrm{mm})$, negatively affects the growth, development and ripening of fruits, the laying of generative buds of the next year's harvest. 


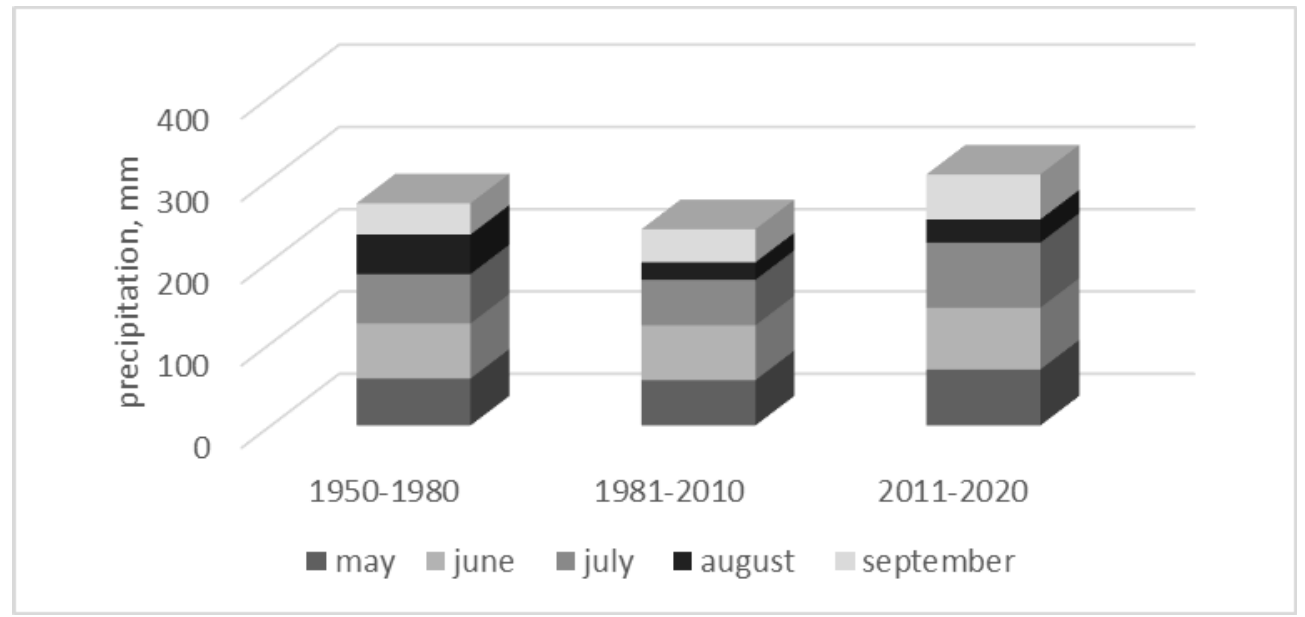

Fig. 2. The amount of precipitation during the growing season of the apple tree (mm) from May to September (Krasnodar, the central subzone of the Kuban zone of the North Caucasian horticultural region, 1950-2020).

However, these conditions, which are negative for the successful growth, fruiting and development of the apple tree, at the same time make it possible to select the most resistant to drought, fungal pathogens, stable fruiting grades, especially highlighting genotypes with commercially attractive fruits, with improved taste and long shelf life.

The obtained data of long-term variety testing of apple genotypes in the conditions of the Western Ciscaucasia made it possible to identify grades and forms of apple trees of domestic breeding that are immune to scab or exhibit increased resistance to it, characterized by adaptability to the complex of abiostressors of the region (drought, unstable moisture regime in summer, spring frosts): Orpheus (Golden Delishes 4X $\times$ OR18T13 (Wolf River $\times($ Wolf River $\times$ M. atrosanguinea $804 / 240-57)$ ); Pomegranate, 12/2-21-35, 12/2-20-56, 12/1-21-27 (Idared $\times$ Balcgard 0247E), 12/1-21-60 (Golden Delishes 4X × 2034 (F2 M. floribunda $\times$ Golden Delishes)); 12/2-20-22, 12/2-20-75 (Korei $\times$ Prima); 12/1-21-6 (Stark John Grayms $\times$ Prima), 12/2-20-36 (Royal Red Delicious $\times 13-83-88$ (Antonovka flat $\times$ Incomparable)); created as part of complex research by breeders of the NCFSCHVW together with VNIISPK (Figure 3, Table 3).

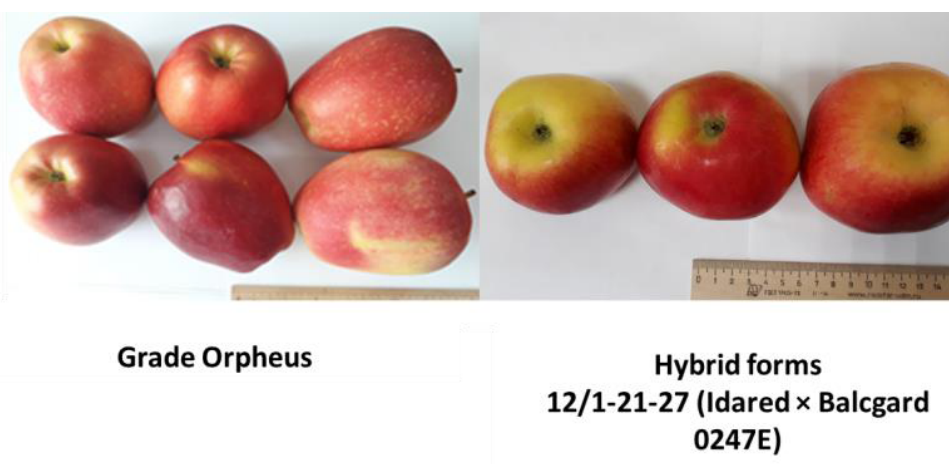

Fig. 3. New genotypes of apple trees of domestic selection, isolated in the conditions of the Western Ciscaucasia. 
Table.1. Assessment of the yield and weight of the fruit of apple varieties and forms, 2010-2020 (the experimental production farm "Centralnoye", NCFSCHVW, Krasnodar, central subzone of the Kuban zone of the North Caucasian region of horticulture).

\begin{tabular}{|c|c|c|c|c|c|c|c|}
\hline \multirow{3}{*}{ grade, form } & \multirow{3}{*}{ ploidy } & \multicolumn{2}{|c|}{ fruit weight, $g$} & \multicolumn{4}{|c|}{ yield $(2010-2020$ гг.) } \\
\hline & & \multirow{2}{*}{$\mathbf{m}_{\text {cp. }}$} & \multirow{2}{*}{$\mathbf{m} \max$} & \multicolumn{2}{|c|}{ average } & \multicolumn{2}{|c|}{ total } \\
\hline & & & & $\mathrm{kg} /$ tree & t/he & kg/tree & t/he \\
\hline Pomegranate* & $2 n=2 x$ & 173,8 & 221,5 & 19,45 & 25,93 & 213,95 & 285,23 \\
\hline $12 / 2-21-35^{*}$ & $2 n=3 x$ & 218,1 & 286,5 & 21,11 & 28,14 & 232,21 & 309,54 \\
\hline $12 / 1-21-60 *$ & $2 n=2 x$ & 202,3 & 224,8 & 25,22 & 33,62 & 277,42 & 369,82 \\
\hline $12 / 2-20-22^{*}$ & $2 n=2 x$ & 178,5 & 210,5 & 23,50 & 31,33 & 258,50 & 344,63 \\
\hline Orpheus* & $2 n=2 x$ & 204,5 & 278,8 & 18,25 & 24,32 & 200,75 & 267,52 \\
\hline $12 / 2-20-75^{*}$ & $2 n=2 x$ & 196,4 & 223,5 & 25,57 & 34,08 & 281,27 & 374,88 \\
\hline $12 / 2-20-48^{*}$ & $2 n=2 x$ & 155,6 & 190,8 & 16,38 & 21,83 & 180,18 & 240,13 \\
\hline $12 / 2-20-56^{*}$ & $2 n=3 x$ & 201,4 & 297,2 & 21,05 & 28,06 & 231,55 & 308,66 \\
\hline 12/1-21-27* & $2 n=3 x$ & 317,9 & 387,2 & 17,66 & 23,54 & 194,26 & 258,94 \\
\hline $\begin{array}{l}\text { Margot* } \\
\text { (control) }\end{array}$ & $2 n=2 x$ & 194,5 & 281,6 & 18,43 & 24,56 & 202,73 & 270,16 \\
\hline $\mathrm{LSD}_{05}$ & & 4,73 & 5,46 & 1,29 & 1,49 & 4,29 & 4,96 \\
\hline
\end{tabular}

Note: * - grade, form have the Rvi-6 (Vf) gene of immunity to scab according to the DNA analysis performed in the breeding and biotechnological laboratory of the FSBSI NCFSCHVW.

The rather high potential for the adaptability of these genotypes may be due to the fact that the pedigree of most of the isolated samples contained wild species, polyploid grades and forms, interspecific hybrids, and ancient grades.

Identified with high productivity potential as diploid: 12/1-21-60, 12/2-20-22, 12/2-20-75, and triploid genotypes: 12/2-21-35, 12/2-20-56 (average yield 28.06-34.08 t/ha; total - up to $374.88 \mathrm{t} / \mathrm{ha}$ ). In terms of large fruit size, the following were identified as diploids: Orpheus and 12/1-21-60 (average fruit weight 202.3-204.5 g, maximum - 224.8$278.8 \mathrm{~g}$ ), and triploid varieties and elite forms (all from the family Idared $\times$ Balcgard 0247E): 12/2-21-35, 12/2-20-56, 12/1-21-27 (average fruit weight 201.4-317.9 g, maximum - 286.5-387.2 g).

\section{Discussion}

One of the most important directions of world apple breeding is a combination of improved commercial characteristics of fruits with high adaptive potential $[23,24]$. In the years of the strongest manifestation and negative impact of stress factors on the fruit plant, the high potential of its productivity is due to the increased adaptive potential [25].

It is known that the emerging weather and climatic conditions of the apple-tree cultivation region, especially having a negative, negative impact on the growth processes and the production potential of this fruit crop, makes it possible for breeders in the world to select genotypes for a set of important traits, highlighting grades and forms with the desired combination of increased adaptability to the stressors of the region, as well as a high yield and improved quality of fruits, allowing to obtain products that are commercially attractive and in demand by the consumer, with a long shelf life $[20,21,26]$. Often, the presence in the pedigree of the studied apple genotype of species and interspecific forms and grades obtained on their basis, as well as an increase in the level of ploidy, increases the potential for resistance to stress factors in the cultivation region [2, 27-30]

The duration and multitasking of the breeding process in fruit crops, the complexity, labor intensity and duration of its many stages dictate the need for widespread use of 
biodiversity and all available genetic potential of crops, as well as system analysis and scientific research. Justified selection of the most valuable source material for use in breeding perennial plants, including apple trees [20, 21, 29]. When drawing up and implementing breeding programs, it should be remembered that genetic diversity is the basis for the process of accelerated breeding of promising grades of fruit plants [21, 31, 32].

The combination of high parameters of adaptation and resistance of the apple plant to biotic and abiotic stress factors and their complex is important for a more successful realization of the productivity potential of modern assortment grades. The data we obtained $[14,19]$, as well as the data of a number of Russian scientists, confirm that that quite often the grades of domestic breeding are superior to foreign ones in adaptability to the complex of stress factors in the cultivation region [33-35].

\section{Conclusion}

In recent years, the increase in the strength and frequency of the negative influence of the region's abio- and biostressors on a perennial plant makes it possible to select the best samples of the gene pool, combining improved commercial characteristics and increased adaptability in the region. According to long-term test results in the North in the Caucasus region, elite forms that are promising for breeding have been identified: 12/1-21-60, $12 / 2-20-22,12 / 2-20-75,12 / 2-21-35,12 / 2-20-56$, immune to scab, with increased adaptability to the complex effect of abiostressors in the region, with a high productivity potential (with an average yield of 28.06-34.08 t/ha; total - up to $374.88 \mathrm{t} / \mathrm{ha}$ ). Allocated on the basis of large-fruited: Orpheus, 12/1-21-60, 12/2-21-35, 12/2-20-56, 12/1-21-27 (average fruit weight 202.3-317.9 g) for the further creation of high quality southern grades.

\section{References}

1. K. Evans, C. Peace, Burleigh Dodds Science Publish (2017)

2. E.N. Sedov, G.A. Sedysheva, Z.M. Serova, S.A. Korneeva, Agrobiology, 51 (2016)

3. E.N. Sedov, Russ J. Genet: Appl Res, 4, 1 (2014)

4. G.V. Eremin, Proceedings on applied botany, genetics and breeding, 181, 4 (2020)

5. E.V. Ulyanovskaya, E.A. Belenko, BIO Web of Conferences, 25 (2020)

6. G.V. Eremin, Acta Hortic., 966 (2012)

7. E.N. Sedov, G.A. Sedysheva, Z.M. Serova, N.G. Gorbacheva, S.A. Melnik, Russ. J. Genet. Appl. Res., 17, 3 (2013)

8. E.V. Ulyanovskaya, T.G. Prichko L.D., Chalaya Russ. J. Genet. Appl. Res., 20, 5 (2016)

9. E.N. Sedov, G.A. Sedysheva, M.A. Makarkina, Z.M. Serova Russ. J. Genet. Appl. Res., 7, 7 (2017)

10. X.S. Chen, M.Y. Han, G.L. Su, F.Z. Liu, G.N. Guo, Y.M. Jiang, Z.Q. Mao, F.T. Peng, H.R. Shu, J. Fruit Sci., 27 (2010)

11. V.S. Girichev, V.A. Visotskii, L.A. Marchenko, L.V. Alekseenko, A.A. Danilova, A.V. Artyukhova, Agricultural Biology, 47, 5 (2012)

12. N. Wang, Y. Zheng, N. Duan, Z. Zhang, X. Ji, S. Jiang, S. Sun, L. Yang, Y. Bai, Z. Fei, X. Chen, PLoS ONE, 10, 7 (2015)

13. Z. Ozherelieva, E. Sedov, Proceedings of the Latvian Academy of Sciences, Section B., Natural, Exact, and Applied Sciences, 71, 3 (2017)

14. N.I. Nenko, G.K. Kisileva, E.V. Ulianovskaya, A.V. Karavaeva, E.K. Yablonskaya, EurAsian Journal of BioSciences, 12, 1 (2018)

15. E.N. Sedov, Russ. J. Genet. Appl. Res., 19, 1 (2015) 
16. D. F. Holderbaum, T. Kon, M. P. Guerra, Sci. Hort., 168 (2014)

17. J. Urrestarazu, C. Denancé, E. Ravon, A. Guyader, R. Guisnel, L. Feugey, L. Feugey, C. Poncet, M. Lateur, P. Houben, M. Ordidge, F. Fernandez-Fernandez, K.M. Evans, F. Paprstein, J. Sedlak, H. Nybom, L. Garkava-Gustavsson, C. Miranda, J. Gassmann, M. Kellerhals, I. Suprun, A.V. Pikunova, N.G. Krasova, E. Torutaeva, L. Dondini, S. Tartarini, F. Laurens, C.-E. Durel, BMC Plant Biol., 16, 1 (2016)

18. I.M. Kulikov, L.A. Marchenko, Her. Russ. Acad. Sci., 87, 2 (2017)

19. N.I. Nenko, G.K. Kiseleva, E.V. Ulyanovskaya, E.K. Yablonskaya, A.V. Karavayeva, Agricultural Biology, 54, 1 (2019)

20. Program and methodology for the study of grades of fruit, berry and nut crops, $\mathbf{6 0 6}$ (1999)

21. E.A. Egorov, G.V. Eremin, Modern methodological aspects of the organization of the selection process in horticulture and viticulture: monograph, $\mathbf{5 6 9}$ (2012)

22. The program of the North Caucasian Center for the selection of fruit, berry, flower and ornamental crops and grapes for the period until 2030, 202 (2013)

23. O. Frøynes, D. Kviklys, M. Meland, NIBIO Rapport, 44, 7 (2021)

24. F. Ramirez, J. Kallarackal, SpringerBriefs in Plant Science, 42, 1 (2015)

25. Rod J. Snowdon, Benjamin Wittkop, Tsu-Wei Chen \& Andreas Stahl, Theoretical and Applied Genetics, 134 (2021)

26. R. Rai, S. Joshi, S. Roy, O. Singh, M. Samir, A. Chandra, J. Horticulture, 2 (2015)

27. E.N. Sedov, G.A. Sedyshev, Z.M. Serova, Monograph, 368 (2008)

28. E.N. Sedov, G.A. Sedyshev, Z.M. Serova, E.V. Ulyanovskaya, Agrarian Bulletin of the Urals, 75, 9 (2010)

29. E.N. Sedov, Monograph, 624 (2011)

30. A.S. Lyzhin, N.N. Savel'eva, Proceedings of the National Academy of Sciences of Belarus, agrarian series, 59, 1 (2021)

31. C. Fischer, K. Richter Erwerbsobstbauu, 41, 2 (1999)

32. J. Keulemans, 28th Internat. Hort. Congr, 202, 1 (2010)

33. E.A. Egorov, I.A. Ilyina, T.G. Prichko, Adaptive potential of garden cultures of the South of Russia in the conditions of stressful temperatures of the winter period, 157 (2006)

34. N.N. Savelyeva, N.I. Savelyev, Optimization of tekhnologo-economic parameters of structure of agrotsenoz and regulations of cultivation of fruit crops and grapes, 1 (2008)

35. E.N. Sedov, G.A. Sedysheva, V.V. Zhdanov, E.V. Ulyanovskaya, Z.M. Serova, Herald VOGiS, 13, 4 (2009) 